\title{
NANOSILVER VERSUS POVIDONE IODINE DRESSING- EFFICACY IN THE MANAGEMENT OF CHRONIC DIABETIC FOOT ULCERS
}

\author{
Abdur Rahaman'1, Akshatha Manjunath2, Aparajita Mookherjee Bhattacharya ${ }^{3}$ \\ ${ }_{1}^{1}$ Postgraduate Student, Department of General Surgery, Vydehi Institute of Medical Sciences and Research Centre, Bangalore. \\ ${ }^{2}$ Assistant Professor, Department of General Surgery, Vydehi Institute of Medical Sciences and Research Centre, Bangalore. \\ 3Professor, Department of General Surgery, Vydehi Institute of Medical Sciences and Research Centre, Bangalore.
}

\section{ABSTRACT}

\section{BACKGROUND}

Foot ulcers are common surgical problems in India due to the habit of barefoot walking, compounded by the increase in the incidence of Diabetes Mellitus. Treatment of chronic leg ulcers remains a constant surgical and medical challenge. Wound healing is a complex process of inflammation, proliferation of growth factors, angiogenesis and matrix \& tissue remodelling, with the ultimate goal being speedy recovery with minimal scarring and maximal functions. Multiple topical formulations have played a major role in the management of wounds, of which Povidone iodine and silver have long been known for their antimicrobial properties. Nanotechnology has made available pure silver nano particles with higher surface area to volume ratio, thus imparting better antimicrobial efficacy versus lesser toxicity. This study is an attempt to evaluate the efficacy of Nanosilver dressings versus Povidone iodine dressings.

\section{MATERIALS AND METHODS}

Between November 2014 and May 2016, total of 60 patients of chronic diabetic foot ulcers were admitted in this tertiary care hospital, 30 patients were randomly included in the Povidone iodine dressing group, and 30 patients in the Nanosilver group, to compare the time taken for formation of granulation tissue, time taken for complete healing, duration of hospital stay, and total cost of treatment.

\section{RESULTS}

Patients encountered in this study were between $4^{\text {th }}$ and $6^{\text {th }}$ decades of life with a prominent male preponderance $(83 \%$ in Povidone iodine and $67 \%$ in Nanosilver). All ulcers had slough, so swab was taken for culture sensitivity. Results of reduction of slough and appearance of granulation tissue were documented at the end of each week till 6 weeks of dressing, favourably higher results of healing were seen in Nanosilver group from $2^{\text {nd }}$ week of dressing (17\% vs. $\left.4 \%\right)$. Duration of hospital stay was shorter in Nanosilver group. (Mean difference 6.63 days) and cost of treatment was also significantly less in Nanosilver patients (Mean difference of 3416 INR).

\section{CONCLUSION}

Faster appearance of granulation tissue and preparation for skin grafting was seen in Nanosilver group. Duration of hospital stay and overall cost of treatment was also found to be lesser, hence Nanosilver dressing can be considered as a better option to Povidone iodine in the safe and rapid management of patients with chronic diabetic foot ulcers.

\section{KEYWORDS}

Nanosilver, Povidone iodine.

HOW TO CITE THIS ARTICLE: Rahaman A, Manjunath A, Battacharya AM. Nanosilver versus Povidone iodine dressing- Efficacy in the management of chronic diabetic foot ulcers. J. Evolution Med. Dent. Sci. 2017;6(22):1799-1803, DOI: $10.14260 /$ Jemds/2017/395

\section{BACKGROUND}

Diabetes is the leading cause of non-traumatic lower extremity amputations, a common complication of chronic untreated foot or leg ulcers. Diabetic foot ulcer is a fullthickness penetration of the of the dermis and the ulcer severity is often classified using the Wagner's system ${ }^{1}$ into -

Grade 1 - Superficial Ulcer.

Grade 2 - Deep Ulcer to tendon, bone or joint.

Grade 3 - Ulcer with abscess or osteomyelitis.

Grade 4 - Forefoot gangrene.

Grade 5 - Whole foot gangrene.

Financial or Other, Competing Interest: None.

Submission 08-02-2017, Peer Review 04-03-2017,

Acceptance 10-03-2017, Published 16-03-2017.

Corresponding Author:

Akshatha Manjunath,

Assistant Professor, Department of Surgery,

Vydehi Institute of Medical Sciences and Research Centre,

\#82, Nallurhalli, EPIP Area, Whitefield, Bangalore-560066.

E-mail: akshatha.sujay@gmail.com

DOI: $10.14260 /$ jemds $/ 2017 / 395$
Diabetic foot ulcers are due to a combination of various causes like- peripheral neuropathy, peripheral vascular disease (PAD) and trauma to the foot. ${ }^{2}$

Peripheral sensory neuropathy is one of the major reasons of formation of foot ulcers mainly due to degeneration of the nerve of the extremities, leading to decreased sensation of pain and temperature. ${ }^{3}$

Hence, ulcers develop in the pressure areas of the foot like the heel and the underside or tips of the toes. In addition to sensory loss, some motor deficits and muscle weaknesses also result due to nerve damage. This combination of motor and sensory loss causes a change in the mechanics of the foot leading to undue stress on the pressure areas and ultimately ulcer formation.

Management of diabetic ulcer is a multifaceted approach of change in lifestyle, healthy diet, active control of diabetes, management of comorbidities and ulcer management. Regular debridement followed by use of various dressing materials like hydrogels, foams, iodine, Ionic silver or skin replacement has been in vogue, which help by keeping the 
wound moist for autolytic breakdown and providing an antibacterial environment.

Ionic silver is one of the most proven antimicrobial substance also having antiseptic and anti-inflammatory properties [including action against antibiotic resistant bacteria like Methicillin-Resistant Staphylococcus Aureus (MRSA) and vancomycin-resistant enterococci (VRE)]. ${ }^{4}$

Since ancient times, silver coins were used to disinfect stored water and liquids by Greeks and ancient Americans. ${ }^{5}$

Nanotechnology makes it possible to expand the surface area of silver particles to nano scale, thus increasing the contact period with bacteria or fungi, vastly enhancing the bactericidal and fungicidal effectiveness of silver ions.

This study aims at evaluating the efficacy of Nanosilver dressing versus Povidone iodine dressing in terms of rapidity of healing, early control of infection with appearance of granulation tissue and the overall duration of hospital stay and cost of treatment.

\section{MATERIALS \& METHODS}

Between the period of November 2014 to May 2016, 60 patients of chronic or non-healing diabetic ulcers of the leg or foot ( $>6$ weeks of duration) admitted to our tertiary care hospital were included in this study. The sample size was chosen based on three criteria: the period of study, the average number of diabetic foot ulcers in our institution in the past years and statistical significance. As we had decided on a study period of two years, this sample size was the minimum one for statistically significant results in that time.

Data was collected using a Case Recording proforma (CRP) which included all particulars- take history, clinical findings, routine investigations, diabetic workup, $\mathrm{x}$-ray of foot/leg, and arterial and venous Doppler study and culture sensitivity of discharge from ulcers.

Computer generated random numbers using block randomisation was used to randomise the patients into 2 groups- 30 in the Povidone iodine dressing group and 30 in the Nanosilver dressing group, with the help of sealed numbered envelopes.

Patients having diabetic ulcers associated with peripheral vascular disease and varicose vein (Diagnosed by Doppler Study), osteomyelitis, suffering from malignancy on steroid therapy and not responding to antidiabetic therapy (Readings more than $250 \mathrm{mg} \%$ ) after 2 weeks of therapy were not included in the study group.

All patients were put under strict antidiabetic regime, antibiotic cover (as per culture report) followed by daily debridement and dressing with their respective dressing materials. End point of management was taken as either complete healing of small ulcers or appearance of bacteria free healthy granulation tissue making the patient fit for split skin grafting. The study parameters included-

- $\quad$ Rapidity of healing.

- Control of infection and early granulation.

- Duration of treatment and shorter hospitalisation, thus reducing the loss of working day.

- Overall cost of treatment.

\section{Statistical Analysis}

In this prospective comparative interventional study, statistical analysis was performed by using STATA 11.2 (College Station, TX, USA). Shapiro-Wilk test was used to find the normality. Student's t-test was performed to find the significant difference between the age, length of hospital stay, wound surface area and total cost, expressed as mean and standard deviation. Chi square test has been used to measure the association between the gender, size of ulcer, presence of slough or granulation tissue and expressed as frequency or percentage $\mathrm{p}<0.05$ was considered as statistically significant.

\section{RESULTS}

Patients from both the groups were found comparable in terms of age distribution, gender and surface area of ulcers. Maximum patients were in the age range of 41-60 years, being $70 \%$ in Povidone iodine group and $63.4 \%$ in Nanosilver group. Male preponderance was seen in both the groups$83 \%$ (PI) versus $67 \%$ (Nanosilver) group. Patients were subdivided into 4 groups as per size of ulcers- $A(<5 \mathrm{~cm}), B(5-7.5$ $\mathrm{cm}), \mathrm{C}(7.5-10)$ and $\mathrm{D}(>10 \mathrm{~cm})$. Both the dressing groups were statistically similar $(p=0.449)$ in the overall number of patients in each of the groups. (Table 1 and Figure I).

\begin{tabular}{|c|c|c|c|c|c|}
\hline \multirow{2}{*}{ Parameters } & \multicolumn{2}{|c|}{ Povidone iodine } & \multicolumn{2}{|c|}{ Nanosilver } & \multirow{2}{*}{\begin{tabular}{|c|}
$p$ \\
value
\end{tabular}} \\
\hline & $\mathrm{N}=\mathbf{3 0}$ & (\%) & $\mathrm{N}=\mathbf{3 0}$ & (\%) & \\
\hline $\begin{array}{c}\text { Age (Years) } \\
0-20\end{array}$ & 0 & $0 \%$ & 0 & $0 \%$ & \multirow{5}{*}{0.478} \\
\hline $21-40$ & 8 & $26.70 \%$ & 10 & $33.30 \%$ & \\
\hline $41-60$ & 21 & $70 \%$ & 19 & $63.40 \%$ & \\
\hline $61-80$ & 1 & $3.30 \%$ & 1 & $3.30 \%$ & \\
\hline Mean \pm SD & \multicolumn{2}{|c|}{$49.73 \pm 12.48$} & \multicolumn{2}{|c|}{$47.47 \pm 12.13$} & \\
\hline Sex/Male & 25 & $83 \%$ & 20 & $67 \%$ & \multirow{2}{*}{0.135} \\
\hline Female & 5 & $17 \%$ & 10 & $13 \%$ & \\
\hline $\begin{array}{c}\text { Ulcer size }\left(\mathrm{cm}^{2}\right) \\
\mathrm{A}(<5)\end{array}$ & 4 & $13 \%$ & 9 & $30 \%$ & \multirow{4}{*}{0.449} \\
\hline $\mathrm{B}(5-7.5)$ & 7 & $23 \%$ & 5 & $17 \%$ & \\
\hline$C(7.5-10)$ & 6 & $20 \%$ & 6 & $20 \%$ & \\
\hline $\mathrm{D}(>10)$ & 13 & $43 \%$ & 10 & $33 \%$ & \\
\hline
\end{tabular}

p value $<0.05=$ significant $^{*}$

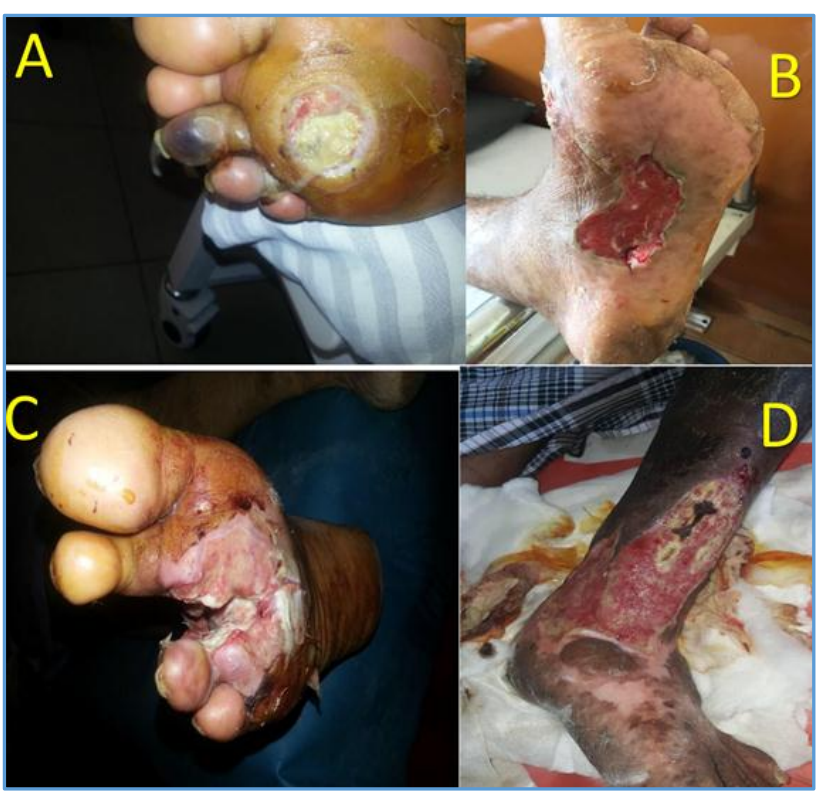

Figure I. Groups of Ulcers According to Size 
Comparison of Reduction of Slough with Appearance of Granulation Tissue Based on the Bacterial Load

Number of patients with ulcer slough in either group (at admission and after 1 week of dressing) were insignificant $(p=1.000)$. At the end of $2^{\text {nd }}$ week, 26 patients $(87 \%)$ in PI group and only 13 patients (43\%) in NS group had slough present, which was statistically significant $(p=<0.001)$. Similarly, at the end of $3^{\text {rd }}$ and $4^{\text {th }}$ week, faster appearance of healthy granulation tissue was seen in the NS group patients $26(87 \%)$ and $29(97 \%)$ respectively, versus the PI group patients, which showed $9(30 \%)$ and $18(60 \%)$ respectively, which was highly significant statistically $(\mathrm{p}=<0.001)$. By the end of the $5^{\text {th }} \& 6^{\text {th }}$ week, all patients in either group had no slough and had healthy granulation tissue fit for split skin grafting. (Figure II \& III).
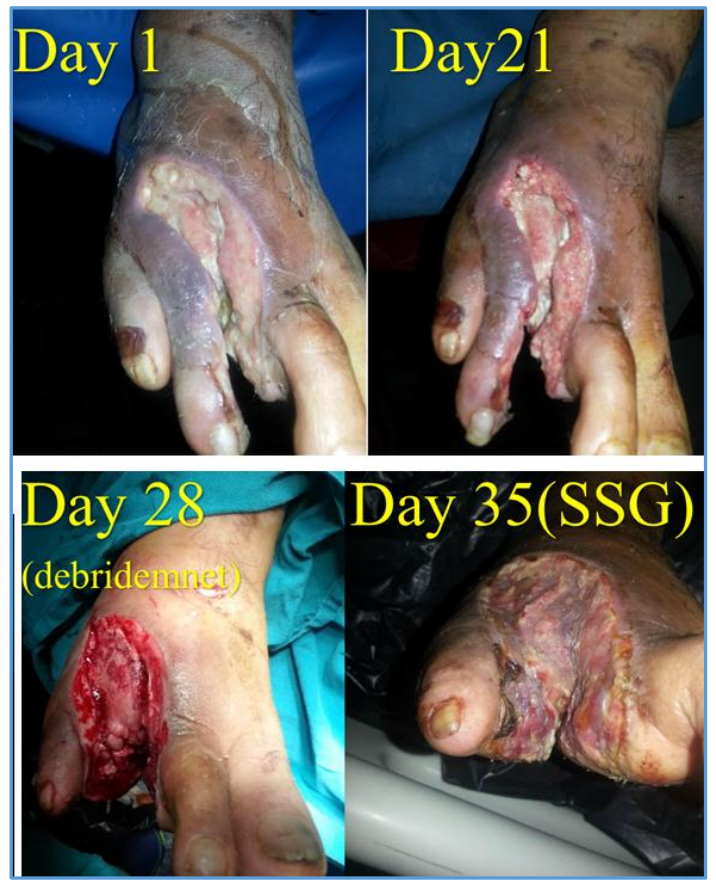

Figure II. Outcome of Dressing with Povidone iodine

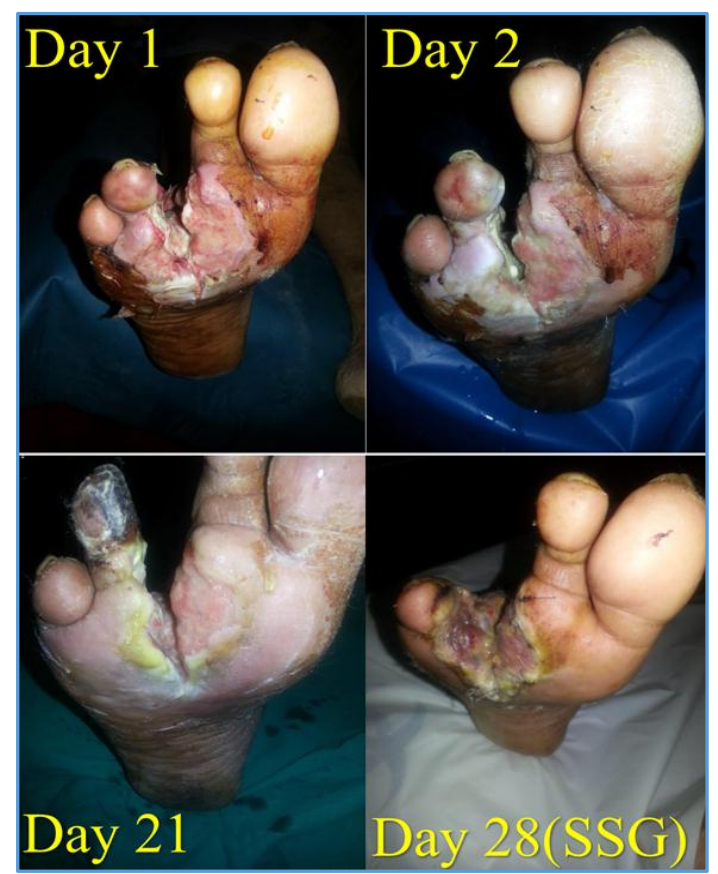

Figure III. Outcome of Dressing with Nanosilver
During the course of dressing, major organisms encountered in both the groups were Haemophilus (6 patients), Klebsiella ( 9 patients), Proteus ( 9 patients), Pseudomonas (10 patients), Staphylococcus Aurous (15 patients) and Streptococcus (11 patients). There was no significant statistical difference during pre-dressing $(p=0.844)$ and post dressing swabs were also not significant $(\mathrm{p}=0.720)$. But decrease in the bacterial load was achieved faster in NS group patients as depicted in Table 2.

\begin{tabular}{|c|c|c|c|c|c|}
\hline \multirow{2}{*}{ Parameters } & \multicolumn{2}{|c|}{ Povidone iodine } & \multicolumn{2}{|c|}{ Nanosilver } & \multirow{2}{*}{ p-Value } \\
\hline & $\mathrm{N}=30$ & $\%$ & $\mathrm{~N}=\mathbf{3 0}$ & $\%$ & \\
\hline \multicolumn{6}{|c|}{ 1. Presence of Slough } \\
\hline Baseline (Day 1) & 29 & 97 & 29 & 97 & 1.000 \\
\hline 1 Week ( $7^{\text {th }}$ day) & 28 & 93 & 24 & 80 & 0.129 \\
\hline 2 Weeks (14th day) & 26 & 87 & 13 & 43 & $<0.001$ \\
\hline 3 Weeks (21'st day) & 21 & 70 & 4 & 13 & $<0.001$ \\
\hline 4 Weeks (28 ${ }^{\text {th }}$ day) & 12 & 40 & 1 & 3 & $<0.001$ \\
\hline 5 Weeks (35th day) & 6 & 20 & 0 & 0 & $<0.001$ \\
\hline 6 Weeks (42nd day) & 0 & 0 & 0 & 0 & $<0.001$ \\
\hline \multicolumn{6}{|c|}{ 2. Appearance of Granulation Tissue } \\
\hline Baseline (Day 1) & 1 & 3 & 1 & 3 & 1.000 \\
\hline 1 Week ( $7^{\text {th }}$ day) & 2 & 7 & 6 & 20 & 0.129 \\
\hline 2 Weeks (14th day) & 4 & 13 & 17 & 57 & $<0.001$ \\
\hline 3 Weeks (21'st day) & 9 & 30 & 26 & 87 & $<0.001$ \\
\hline 4 Weeks (28 ${ }^{\text {th }}$ day) & 18 & 60 & 29 & 97 & $<0.001$ \\
\hline 5 Weeks ( $35^{\text {th }}$ day) & 24 & 80 & 30 & 100 & $<0.001$ \\
\hline 6 Weeks (42nd day) & 30 & 100 & 30 & 100 & $<0.001$ \\
\hline \multicolumn{6}{|c|}{ 3. Bacterial Load Pre-Dressing } \\
\hline Haemophilus & 3 & 10 & 3 & 10 & \multirow{6}{*}{0.844} \\
\hline Klebsiella & 4 & 13 & 5 & 17 & \\
\hline Proteus & 4 & 13 & 5 & 17 & \\
\hline Pseudomonas & 6 & 20 & 4 & 13 & \\
\hline Staphylococcus & 9 & 30 & 6 & 20 & \\
\hline Streptococcus & 4 & 13 & 7 & 23 & \\
\hline \multicolumn{5}{|l|}{ Post-dressing } & \multirow{6}{*}{0.720} \\
\hline Nil & 23 & 77 & 25 & 83 & \\
\hline Haemophilus & 1 & 3 & 1 & 3 & \\
\hline Proteus & 0 & 0 & 1 & 3 & \\
\hline Pseudomonas & 4 & 13 & 2 & 6 & \\
\hline Staphylococcus & 2 & 6 & 1 & 3 & \\
\hline
\end{tabular}

Table 2. Comparison of Slough versus Granulation Tissue and Bacterial Load of Ulcers

$\mathrm{p}$ value $<0.05=$ significant $*$

\section{Outcomes of Ulcer Management}

Mean size of ulcer during admission \& after six weeks in PI group was $10.13+-5.94$ and $9.28+-4.94$ respectively. While in NS group it was $8.95+-5.81$ and $7.00+-4.29$ respectively. $P$ value was not found to be statistically significant.

On comparing the outcome of ulcer healing up to 6 weeks in PI group, 4 patients (100\%) in group A, 2 patients (29\%) in group B and 1 patient $(17 \%)$ in group $C$ showed complete ulcer healing, whereas this figure in NS group was 9 patients $(100 \%)$ in group A, 2 patients (40\%) in group B and 1 patient $(17 \%)$ in group C. Remaining patients had to be taken up for split thickness skin grafting. The total duration of hospital stay was significantly shorter in NS group patients with a mean difference of 6.63 days ( $p=0.002^{*}$ ) and the overall cost of the treatment was found to be higher in PI group with a mean difference of INR 3416 and significant $p$ value of $0.023^{*}$. (Table III). 


\begin{tabular}{|c|c|c|c|c|c|c|c|c|}
\hline arameters & \multicolumn{3}{|c|}{$\begin{array}{c}\begin{array}{c}\text { Povidone iodine } \\
\mathrm{N}=30\end{array} \\
\end{array}$} & \multicolumn{3}{|c|}{$\begin{array}{c}\text { Nanosilver } \\
\mathrm{N}=30\end{array}$} & \multirow[t]{2}{*}{ Mean Difference } & \multirow[t]{2}{*}{$\begin{array}{c}\begin{array}{l}P- \\
\text { Value }\end{array} \\
\end{array}$} \\
\hline $\begin{array}{l}\text { 1. Outcome of healing } \\
\text { (till } 6 \text { weeks) }\end{array}$ & Healed & SSG & Flap & & & & & \\
\hline Group A(4) & $4(100 \%)$ & - & - & & & & & \\
\hline $\mathrm{B}(7)$ & $2(29 \%)$ & $5(71 \%)$ & - & & & & & \\
\hline $\mathrm{C}(6)$ & $1(17 \%)$ & $5(83 \%)$ &  & & & & & \\
\hline \multirow[t]{2}{*}{$\mathrm{D}(13)$} & - & $12(92 \%)$ & $1(8 \%)$ & & & & & \\
\hline & & & & Healed & SSG & Flap & & \\
\hline Group A(9) & & & & $9(100 \%)$ & & - & & \\
\hline$B(5)$ & & & & $2(40 \%)$ & $3(60 \%)$ & - & & \\
\hline C (6) & & & & $1(17 \%)$ & $5(83 \%)$ & - & & \\
\hline $\mathrm{D}(9)$ & & & & - & $8(89 \%)$ & $1(11 \%)$ & & \\
\hline \multicolumn{9}{|l|}{$\begin{array}{l}\text { 2. Wound surface } \\
\text { area }\left(\mathrm{cm}^{2}\right) \\
(\text { mean } \pm \mathrm{SD})\end{array}$} \\
\hline Baseline (day 1) & \multicolumn{3}{|c|}{$10.13 \pm 5.94$} & \multicolumn{3}{|c|}{$8.95 \pm 5.81$} & 1.18 & 0.390 \\
\hline 1 Week (7th day) & \multirow{2}{*}{\multicolumn{3}{|c|}{$\frac{10 \pm 5.91}{9.40 \pm 6.24}$}} & \multicolumn{3}{|c|}{$8.75 \pm 5.78$} & 1.25 & 0.366 \\
\hline 2 Weeks (14th day) & & & & \multirow{2}{*}{\multicolumn{3}{|c|}{$\begin{array}{l}8.19 \pm 5.37 \\
9.14 \pm 4.61\end{array}$}} & 1.21 & 0.443 \\
\hline 3 Weeks (21st day) & \multicolumn{3}{|c|}{$9.18 \pm 5.85$} & & & & 0.982 & 0.943 \\
\hline 4 Weeks (28 th day) & \multicolumn{3}{|c|}{$9.02 \pm 5.78$} & \multicolumn{3}{|c|}{$8.57 \pm 4.12$} & 0.45 & 0.816 \\
\hline 5 Weeks ( $35^{\text {th }}$ day $)$ & \multicolumn{3}{|c|}{$9.15 \pm 5.13$} & \multicolumn{3}{|c|}{$9.10 \pm 3.38$} & 0.05 & 0.713 \\
\hline 6 Weeks (42 nd day) & \multicolumn{3}{|c|}{$9.28 \pm 4.94$} & \multicolumn{3}{|c|}{$7.00 \pm 4.29$} & 2.28 & 0.395 \\
\hline $\begin{array}{c}\text { 3. Hospital stay } \\
\text { (days) }(\text { mean } \pm \text { SD) }\end{array}$ & \multicolumn{3}{|c|}{$37.43 \pm 6.93$} & \multicolumn{3}{|c|}{$30.80 \pm 9.00$} & 6.63 & $0.002^{*}$ \\
\hline $\begin{array}{l}\text { 4. Total Cost (INR) } \\
(\text { mean } \pm \text { SD) }\end{array}$ & \multicolumn{3}{|c|}{$14833.33 \pm 6156.48$} & \multicolumn{3}{|c|}{$11416.67 \pm 5635.61$} & 3416 & $0.023^{*}$ \\
\hline
\end{tabular}

$\mathrm{p}$ value $<0.05=$ significant $*$

\section{DISCUSSION}

Mainstay of treatment of Diabetic foot ulcer (DFU) is surgical debridement and use of variable solutions or materials for bio-degradable therapy. Selecting an appropriate dressing agent is a major decision for affective disinfection and removal of necrotic tissue from ulcers aimed at modifying the microcondition of wounds and to enhance wound healing in this prospective randomised clinical trial conducted on 60 patients with chronic leg/foot ulcers due to diabetes. The study group of 60 patients were divided into two equal and comparable groups of 30 patients each in Povidone iodine group and Nanosilver group. Both groups were found comparable in terms of age, sex, size of ulcers, presence of slough and bacterial load at the time of admission.

Very few series are available which compare the outcomes of ulcer management between Povidone iodine and Nanosilver dressing, hence our series has been a learning experience towards a comparative analysis. In the study conducted by Kapur V \& Marwaha AK, 6 they reported $90 \%$ decrease in slough by 18 days ( $2^{\text {nd }}-3^{\text {rd }}$ weeks) with Povidone iodine, whereas in this series the result was not comparable as only $60 \%$ decrease of slough was seen by the $4^{\text {th }}$ week of treatment in Povidone iodine. And 90\% decrease was seen only after the $5^{\text {th }}$ week. Hence time taken for decrease of slough is longer in this study for the PI group patients.

Comparing the results of Povidone iodine vs. Nanosilver, Singh $\mathrm{S}$ and Apte $\mathrm{A}^{7}$ in their study reported that mean time taken for slough reduction in NS group was 11.6 days $\left(2^{\text {nd }}\right.$ week) and 18.91 days ( 3 rd week) in PI group with a p value of $<0.0001$. But in our study Nanosilver Group patients showed $87 \%$ of slough reduction in $3^{\text {rd }}$ week $(\mathrm{p}<0.001)$ and $97 \%$ by $4^{\text {th }}$ week $(\mathrm{p}<0.001)$.
This longer time taken than the comparative study can probably be attributed to the time taken for active control of diabetes. Appearance of granulation tissue was seen in $10 \%$ of patients in PI group and in $57 \%$ patients of NS group at the end of $2^{\text {nd }}$ week of dressing with a significant $p$ value $<0.001$.

Comparing the overall reduction in surface area of ulcers in either groups, Ramanaiah NV and Saikrishna et al ${ }^{8}$ found it to be $94.81 \%$ in NS group vs. $84.69 \%$ in PI group, which was statistically significant. But there is no mention of the time taken for this percentage reduction and hence not equally comparable with the present study, where we found change of ulcer size from $8.95+-5.81 \mathrm{~cm}^{2}$ to $7.00+-4.29 \mathrm{~cm}^{2}$ at the end of 6 weeks in NS patients and from $10.13+-5.9 \mathrm{~cm}^{2}$ to $9.28+-4.94 \mathrm{~cm}^{2}$ in the same duration in PI patients. Our study highlighted that the type of dressing material did not cause any significant difference in the reduction of ulcer size.

Singh $S$ and Apte $A^{7}$ in their study found that mean time for achieving no growth status in Iodine group was 14.63 days and 9.60 days in NS group which was statistically significant $(\mathrm{p}<0.001)$. But in our study, both groups were found to be statistically identical in pre-dressing stage $(\mathrm{p}=$ $0.844)$ and post-dressing stage $(p=0.720)$ in terms of achieving organism-free status for further management. But the bacteria-free state was achieved earlier in NS group than PI Group, hence significantly reducing hospital stay.

In one study, hospital stay was significantly shorter in NS group (30.0 +- 9.09 days) vs. PI group (37.43 +- 6.93 days $)$ and also statistically significant $(\mathrm{P}<0.002)$. Our results are comparable with that of Ramanaiah et al ${ }^{8}$ who also found a statistically significant $(\mathrm{P}<0.001)$ shorter stay in their study in the NS group of patients.

Due to this shorter duration of stay, patients of NS group spent approximately $11416.67+-5635.61$ (INR) in our study, whereas the other group spent $14833.33+-6165.48$ (INR), 
with a mean difference of 3414 INR which was statistically significant ( $p<0.023$ ). No comparable studies were found in terms of total expenditure incurred in either group but in the study of Stephens R, Silverstein $\mathrm{P}$ et al, ${ }^{9} 33 \%$ reduction in labour and supply costs was observed when silver was used compared to other standard treatments.

\section{CONCLUSION}

Diabetic foot ulcer is not only a serious problem for the patient, but also a major health care concern in terms of loss of man days and prohibitive cost of treatment. Povidone iodine has been in use for dressing of ulcers for a long time with good results as proved in numerable studies. But Nanosilver is a relatively new compound and has not been as widely in use as Povidone iodine. It has shown some promising results in this study, both in terms of duration of hospital stay and overall lower cost of treatment. But, since not many studies have been conducted with this compound, there is limited comparison with other studies. So, the need is for more experimentation and confirmation of the efficacy of Nanosilver to achieve faster and better healing in patients of diabetic foot ulcer. Goal of our study was to compare both the compounds in terms of achieving better wound healing and to ascertain the efficacy of Nanosilver in comparison to Povidone iodine.

Hence, we conclude that NS can be considered as a better option to Povidone iodine in rapid and safe management of all patients with foot/leg ulcers of diabetic origin.

\section{REFERENCES}

[1] Shah JB. The history of wound care. J Am Col Certif Wound Spec 2011;3(3):65-6.
[2] Masharani U. Diabetes mellitus \& hypoglycemia. In: Quinn GR, McPhee SJ, Papadakis MA, et al, eds. Current medical diagnosis \& treatment. 55 $5^{\text {th }}$ edn. New York: McGraw-Hill Professional Lange Medical Book 2012:1192-5.

[3] Green B, Zoepke A. Diabetes and diabetic foot ulcers: an often hidden problem. S Afr Fam Pract 2013;80(4):32-6.

[4] Lansdown AB, Jensen K, Jensen MQ. Contreet foam and Contreet hydrocolloid: an insight into two new silver containing dressings. J Wound Care 2003;12(6):20510.

[5] Jurczak F, Dugré T, Johnstone A, et al. Randomised clinical trial of Hydrofiber dressing with silver versus povidone-iodine gauze in the management of open surgical and traumatic wounds. Int Wound J 2007;4(1):66-76.

[6] Kapur V, Marwaha AK. Evaluation of effect and comparison of superoxidised solution (oxum) v/s povidone iodine (Betadine). Indian J Surg 2011;73(1):48-53.

[7] Singh S, Apte A. Comparative study of silver foam dressing over povidone iodine dressing in infected wounds. Journal of Evolution of Medical and Dental Sciences 2014;3(22):6233-42.

[8] Ramanaiah NV, Saikrishna. A clinical study on efficacy of nanocrystalline silver dressing in diabetic foot ulcers. Journal of Evidence Based Medicine and Healthcare 2015;2(45):8160-70.

[9] Stephens R, Silverstein P. An evaluation of ACTICOAT dressing with regard to cost and control of infection. Burns 2004;30(1):1-9. 